\title{
Cartas al Director
}

\author{
Infección por virus $\mathrm{C}$ oculto en hepatopatías \\ criptogenéticas
}

\section{Sr. Director:}

Desde que Brechot y colaboradores publicaron la primera serie de pacientes con Hepatitis B crónica sin hallazgo del antigeno de superficie en el suero (1) se ha venido hablando de virus B "oculto".

Nosotros hemos colaborado en un trabajo de reciente publicación (2) en el que se ha estudiado una serie de 100 pacientes con alteración persistente de aminotransferasas y/o gamma-glutamiltranspeptidasa que no podía ser achacada a ninguna de las etiologías habituales, incluyendo la negatividad de los marcadores virales (RNA-HVC, DNA-HVB) y en los que en cambio se encontró, en el 57\%, por hibridación in situ, la presencia del RNA-HVC del genotipo lb en el tejido hepático y con una actividad necroinflamatoria y fibrótica superior a la histología de los pacientes sin RNA-HVC intrahepático.

La reflexión, como clínico, que estos hallazgos implican me han hecho sumarizar las posibles consecuencias del mismo.

Primero, en cuanto al diagnóstico, este hallazgo hecha por tierra la aseveración de que la ausencia en el plasma de marcadores del virus C (preferentemente el RNAHVC) elimina el diagnóstico de Hepatopatía Crónica por virus $\mathrm{C}$ y, áun recogiendo los datos de mayor potencial necróticroinflamatorio y de fibrosis, desconocemos su evolución futura que precisará de seguimiento de estos pacientes.

En cuanto a posibilidad de contagio, no tenemos aún el convencimiento de que el material genómico detectado sea infeccioso, aunque con copias suficientes para identificar el genotipo $1 \mathrm{~b}$. Por otro lado el hecho de que, al menos en nuestra serie, los pacientes presenten elevaciones enzimáticas significativas, elimina el peligro de que puedan ser donantes en bancos de sangre, etc., pudiendo igualmente prevenirse posibles contagios parenterales individuales.

El hecho de no conocer aún la evolución específica de estos enfermos con virus $\mathrm{C}$ oculto, así como su pertenencia al genotipo Ib y que, únicamente por hibridación in situ de una nueva biopsia tras el tratamiento, pueda juzgarse de la eficacia del mismo, implican que, de momento, sólo deban emprenderse seguimientos y tratamientos muy controlados.

\author{
A. Pérez Mota \\ Servicio de Aparato Digestivo. Hospital Virgen de la Torre. \\ Madrid
}

1. Bréchot C, Thiers V, Kremsdorf D, Nalpas B, Pol S, Paterlini-Bréchot P. Persistent hepatitis B virus infection in subjects without hepatitis B surface antigen: clinically significant or purely "occult"?. Hepatology 2001; 34: 194-203.

2. Castillo I, Pardo M, Bartolomé J, Ortiz-Movilla N, Rodríguez-Iñigo E, Lucas S, Salas C, jiménez-Hefferman JA, Pérez-Mota A, Graus J, LópezAlcorcho JM y Carreño V. Occult Hepatitis C Virus Infection in Patients in Whom the Etiology of Persistently Abnormal Results of Liver-Function Tests Is Unknown. J Infect Dis 2004; 189: 7-14.

\section{Reacción leucemoide secundaria a hepatocarcinoma}

\section{Sr. Director:}

El hepatocarcinoma es el tumor primario maligno hepático más frecuente. Una de sus manifestaciones clínicas es la producción de síndromes paraneoplásicos. Entre los más frecuentes se encuentran la poliglobulia, la hipercalcemia, la hipoglucemia y la hiperlipidemia. De forma más rara, se han descrito reacciones leucemoides secundarias a hepatocarcinoma (1-3). El primer caso fue descrito por Ranke y cols. (1) en 1965. Tras realizar una búsqueda bibliográfica en Medline desde 1966-2002 existen escasos artículos publicados referentes a dicho tema y no hemos encontrado ninguno en la literatura española. Presentamos un caso de reacción leucemoide secundaria a hepatocarcinoma.

Se trata de un varón de 79 años, bebedor ocasional sin otros antecedentes de interés, ingresado en el año 2001 con diagnóstico de descompensación hidrópica secundaria a cirrosis hepática con sospecha de hepatocarcinoma. En dicho ingreso presentó en líquido ascítico: 400 hematíes $/ \mathrm{mm}^{3}, 400$ leucocitos $/ \mathrm{mm}^{3}$ (15\% segmentados, $85 \%$ linfocitos), glucosa $136 \mathrm{mg} / \mathrm{dl}$, proteínas tota- 
les 1,2 g/dl, LDH $113 \mathrm{UI} / \mathrm{L}$, ADA 7,3 UI/L, con cultivo y BAAR negativos y citología negativa para células tumorales malignas. Analítica con $\alpha \mathrm{FP} 1393 \mathrm{ng} / \mathrm{ml}$ (valores normales < 15), sin tumoración evidente en los estudios de imagen (ecografía, TAC). Tras evolucionar favorablemente de la ascitis fue dado de alta con tratamiento sintomático. Fue valorado en consulta 4 meses después, se le realizó una ecografía de control en la que se apreció un hígado cirrótico con imágenes sugerentes de lesión focal hepática compatibles con hepatocarcinoma. El paciente no aceptó continuar con el estudio de dicha lesión. Seis meses después, ingresó de nuevo por disnea y descompensación edemoascítica tras incumplimiento del tratamiento diurético, sin presentar en ningún momento fiebre ni datos sugerentes de enfermedad infecciosa. En la exploración destacaba leve ingurgitación yugular, ascitis y edemas en extremidades inferiores. No se palpaban adenopatías. En la analítica destacaba hemograma: 105.700 leucos $/ \mathrm{mm}^{3}$ (96,6\% seg), $96.000 / \mu \mathrm{L}$ plaquetas, serie roja normal, coagulación: act de prot $38 \%$, aPTT 28,9 segundos, fibrinógeno 143 $\mathrm{mg} / \mathrm{dl}$, bioquímica con urea $78 \mathrm{mg} / \mathrm{dl}$, creatinina $1,5 \mathrm{mg} / \mathrm{dl}$, BT $1,49 \mathrm{mg} / \mathrm{dl}$, proteínas totales $6,95 \mathrm{~g} / \mathrm{dl}$, AST $75 \mathrm{UI} / \mathrm{L}$, ALT 60 UI/L, GGT $308 \mathrm{UI} / \mathrm{L}$, amilasa $86 \mathrm{UI} / \mathrm{L}$, LDH $723 \mathrm{UI} / \mathrm{L}$, fosfatasa alcalina 1.007 UI/L (valores normales entre 40-129), $\alpha \mathrm{FP} 1750$ $\mathrm{ng} / \mathrm{ml}$. Fosfatasa alcalina leucocitaria 154 (20-40). Vitamina B12 $>1200 \mathrm{pg} / \mathrm{ml}$ (193-982). Autoanticuerpos ANA, AMA, AML, antiLKM-1 y APCA negativos, antiVHC negativo, HBcAC positivo. Líquido ascítico tras paracentesis: hties $1280 / \mathrm{mm}^{3}$, leucos $1150 / \mathrm{mm}^{3}$ (PMN55\%, 45\% linfos), glucosa $127 \mathrm{mg} / \mathrm{dl}$, prot totales $0,98 \mathrm{~g} / \mathrm{dl}$, ADA 8,3 UI/ml, cultivo y citología negativos. En la ecografía abdominal se observó ascitis en flancos y cirrosis hepática con nódulo hiperecogénico en lóbulo hepático derecho, de 3 $\mathrm{cm}$ sugerente de hepatocarcinoma. En el TAC abdominal se apreciaban además adenopatías metastásicas alrededor del tronco celiaco. Se realizó una punción-aspiración de médula ósea en cresta iliaca, en su examen microscópico se observó una celularidad muy aumentada, con grasa disminuida, megacariocitos cuantitativamente aumentados sin alteraciones morfológicas, serie mieloide muy hiperplasiada con buen gradiente madurativo, existencia de áreas con eosinofilia, serie eritroide con buen gradiente madurativo. El estudio anatomopatológico de la muestra se informó como médula ósea hipercelular reactiva sin evidencia de malignidad hematológica. Los estudios de biología molecular fueron negativos para las expresiones bcr/abl P210 y bcr/abl P190 no detectando traslocaciones bcr/abl p230 ni en ninguna de sus otras formas mediante RT-PCR. El cariotipo de neoplasia hematológicas en médula ósea por técnica de bandas $\mathrm{G}$ no reveló ninguna anomalía citogenética de tipo clonal. El estudio realizado descartó la presencia de neoplasia hematológica. Dada la alta sospecha de hepatocarcinoma compatible con la clínica, los elevados valores de $\alpha \mathrm{FP}$ y las pruebas de imagen y teniendo en cuenta la mala situación clínica del paciente, la familia decidió no realizar PAAF hepática.

De acuerdo con otros autores, ante un paciente con cirrosis hepáticas en el que se detecta una lesión focal compatible con hepatocarcinoma mediante al menos dos técnicas de imagen, el diagnóstico de hepatocarcinoma debe considerarse prácticamente de certeza (4). En nuestro caso, este diagnóstico se ve apoyado por la clínica y los elevados niveles de $\alpha$ FP. Una de las manifestaciones del hepatocarcinoma es la producción de síndromes paraneoplásicos. Dentro de ellos, se describen raramente reacciones leucemoides.

Las reacciones leucemoides son leucocitosis reactivas con número de leucocitos $>50 * 10^{\circ} / 1$, las cuales se subdividen en granulociticas (neutrófilas o eosinófilas) y linfocitósicas (5). Las neutrofílicas suelen ser secundarias a infecciones bacterianas muy graves, anemias hemolíticas, necrosis tisulares y neoplasias $(5,6)$. Cuando se produce como consecuencia de la presencia de tumor se deben a la producción de factores estimulantes de colonias que actúan directamente sobre la médula ósea, a la elevación de los niveles de citocinas secundarias a la necrosis tumoral o a las superinfecciones (6).

Ante toda reacción leucemoide es necesario realizar un diagnóstico diferencial con la mielofibrosis con metaplasia mieloide y los síndromes mieloproliferativos crónicos, sobre todo con la leucemia mieloide crónica, y con la leucemia neutrofílica crónica si no existe desviación izquierda. Para ello debemos realizar frotis de sangre periférica y exámen del aspirado biopsia de médula ósea, fosfatasa alcalina granulocítica, vitamina $\mathrm{B}_{12}$ y estudios de citogenética siendo ésta última la de mayor utilidad (2).

En nuestro caso el estudio de médula ósea y de biología molecular fueron negativos para diagnóstico de leucemia mieloide crónica, leucemia neutrofílica crónica, leucemia aguda mieloblástica ph y leucemia aguda linfoblástica ph de novo. Se hallaron niveles elevados de fosfatasa alcalina compatibles con infección ó neoplasia pero no con leucemia mieloide crónica.

Por tanto, tras descartar las neoplasias hematológicas como causa de la reacción leucemoide y considerando la clínica del paciente compatible con hepatopatía, los niveles de $\alpha \mathrm{FP}>1.750$ ng $/ \mathrm{ml}$ e imágenes compatibles con carcinoma hepatocelular según las técnicas de imagen, el diagnóstico del paciente debe considerarse prácticamente de certeza para carcinoma hepatocelular con reacción leucemoide secundaria. Debido a la diseminación del tumor y el estado clínico del paciente se decidió realizar tratamiento paliativo, falleciendo dos semanas tras el alta.

\section{D. Mañas García, E. Marchán Carranza, J. Galiana Gómez-del Pulgar, F. Ceres Alabau}

Servicio de Medicina Interna. Complejo Hospitalario de Ciudad Real

1. Yuen BH, Reyes CV, Rawal PA, Sosman J, Jensen J. Severe eosinophilia and hepatocellular carcinoma: an unusual association. Diagn Cytopathol 1995; 13: 151-154.

2. Ramos FJ, Zamora F, Perez-Sicilia M, Sang MA, del Villar R. Chronic granulocityc leukemia versus neutrophilic leukemoid reaction. Am J Med 1990; 88: 83-84

3. Rosenfeld CS, Sloan B, Egitto DJ. Multiple hepatoma with leukemoid reaction. N Y State J Med 1982; 82: 359-361.

4. Sala M, Suárez Y, Bruix J. Protocolo diagnóstico-terapéutico del carcinoma hepatocelular. Medicine (Madr) 2000; 8: 647-649.

5. López M, de Miguel D, García J, Burgaleta C. Alteraciones de los leucocitos. Medicine (Madr) 2001; 8: 2735-2742.

6. Dale D. Neutrophilia. En: Butler E, Lichtman MA, Coller BS, Kipps TJ, editors. Williams Hematology 5th ed. USA, 1995. p. 824-828.

\section{Metástasis ósea como primera manifestación de un hepatocarcinoma}

\section{Sr. Director:}

El carcinoma hepatocelular (CHC) es el tumor maligno hepático primario más frecuente. Aunque suele presentarse en hígados cirróticos, excepcionalmente se desarrolla sobre un hígado no cirrótico. Situaciones predisponentes son: La infección por VHB y VHC, la exposición a aflatoxina y las enfermedades crónicas hepáticas (déficit alfa-1-antitripsina, hemocromatosis, cirrosis alcohólica, etc). La presentación macroscópica de CHC es variable. Puede aparecer como un nódulo único, de forma multinodular e incluso difusamente. 
La progresión local y sistémica del $\mathrm{CHC}$ es habitual, menos del $20 \%$ de los casos se restringe al hígado. La infiltración portal tiene lugar en el 35\% de los casos. Las metástasis más frecuentes son en pulmón (35\%) y en ganglios abdominales $(20 \%)$.

Las manifestaciones clínicas del CHC dependen de su fase evolutiva. Aunque es un tumor de crecimiento lento, se tiende a diagnosticar en fases avanzadas de la enfermedad, con la excepción de los pacientes incluidos en programas de seguimiento de hepatopatías crónicas que incluyan valoración ecográfica semestral o anual y determinación simultánea de alfafetoproteína.

Varón de 70 años de edad con antecedentes de diabetes mellitus tipo 2, hipertensión arterial, litiasis renal y colelitiasis. Era portador conocido del VHC desde 1996 pero no había seguido ningún control médico por este motivo.

En diciembre de 2001, comenzó con dolor lumbar irradiado por el flanco derecho, hacia delante y a genitales, que limitaba la deambulación e impedía el descanso nocturno por intolerancia al decúbito. Presentó, además, síndrome constitucional con pérdida de $6 \mathrm{Kg}$ de peso en los dos últimos meses. Había acudido en 2 ocasiones a urgencias refiriendo lumbalgia, realizándose en la primera de ellas una ecografía abdominal que objetivó una lesión compatible con hemangioma hepático de $22 \mathrm{~mm}$ en segmento VII; colelitiasis y esplenomegalia homogénea de $15 \mathrm{~cm}$. En la segunda ocasión, un mes más tarde, se decidió ingreso en el Servicio de Cirugía ante la sospecha de cólico hepático. Durante el ingreso se realizaron dos nuevas ecografías abdominales que confirmaron los hallazgos de la primera ecografía sin que se detectasen más lesiones ocupantes de espacio en el parénquima hepático. Tras consulta al Servicio de Digestivo, se solicitó analítica general en la que destacaba alfafetoproteína de $35350 \mathrm{ng} / \mathrm{ml}$, además de discreta colestasis y anti-VHC positivo.

Dados los hallazgos obtenidos, se realizó TC abdominal que objetivó una lesión ocupante de espacio de $26 \mathrm{~mm}$ de diámetro, que no captaba contraste, en lóbulo hepático derecho y una lesión lítica de unos $5 \mathrm{~cm}$ a nivel vertebral, L1-L2 (Fig. 1). Ante la sospecha de CHC, se derivó al paciente a Oncología, practicándosele ECO-PAAF de la lesión lumbar, resultando compatible con metástasis de $\mathrm{CHC}$, que provocaba destrucción de la zona posterior vertebral y afectación radicular. Se decidió tratamiento sintomático del dolor con radioterapia sobre L1, una única sesión de 8 Gy, consiguiendo junto con la medicación oral, control del dolor y tolerancia al decúbito.

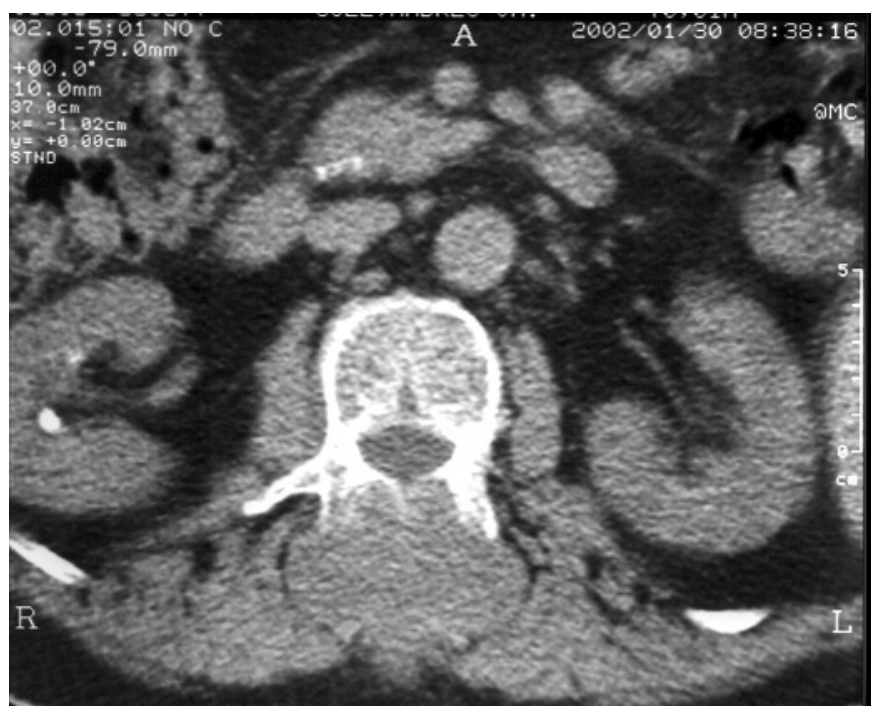

Fig. 1. Detalle de la TC abdominal que muestra la lesión lítica a nivel $L 1$.
El paciente evolucionó desfavorablemente y falleció dos meses más tarde en un centro socio-sanitario.

La mayor supervivencia de los pacientes con $\mathrm{CHC}$ es una de las posibles causas del aumento de la incidencia de metástasis óseas en estos pacientes (1). Las localizaciones más frecuentes son las vértebras, pelvis, costillas y cráneo, en este orden. Para el diagnóstico de estas metástasis se ha propuesto la realización de gammagrafía con Tc-99m (2).

Aunque no es lo habitual, hay casos en los que el diagnóstico de las metástasis óseas precede al del $\mathrm{CHC}$ como en nuestro paciente (3). Recientemente se ha comunicado en nuestro país un nuevo caso de metástasis a nivel esternal (4). La supervivencia de estos pacientes parece no modificarse por la presencia de las metástasis óseas ya que la mayoría de ellos fallecen de causas hepáticas.

El dolor es una de las principales complicaciones de las metástasis óseas. Para su tratamiento se ha propuesto la embolización arterial, la radioterapia externa o una combinación de ambas siendo esta última la más recomendable (5).

Kaizu y cols. recogen la serie más larga con 57 pacientes con metástasis óseas de $\mathrm{CHC}$ tratadas con radioterapia con desaparición del dolor en el 83’3\% de los casos (6).

\section{N. Sanz Arevalillo', F. Bolado Concejo, C. Cardona Castellá, J. J. Giné Gala, M. Llobera Serentill ${ }^{2}$}

Servicios de Aparato Digestivo, ${ }^{1}$ Medicina Interna y ${ }^{2}$ Oncología. Hospital Verge de la Cinta. Tortosa, Tarragona

1. Fukutomi M, Yokota M, Chuman $\mathrm{H}$ et al. Increased incidence of bone metastases in hepatocellular carcinoma. Eur J Gastroenterol Hepatol $2001 ; 13: 1083-8$

2. Sueyoshi K, Narabayashi I, Aratani T et al. Utility of Tc-99m GSA whole-body scintigraphy in detecting bone metastases from hepatocellular carcinoma. Clin Nucl Med 2001; 26: 221-4.

3. Raoul JL, Le Simple T, Le Prise E, Meunier B, Ben Hassel M, Bretagne JF. Bone metastasis revealing hepatocellular carcinoma: a report of theree cases with a long clinical course. Am J Gastroenterol 1995; 90: 1162 4.

4. García de Lucas MD, Jurado Gámez B, Pérez Sicilia M, Trujillo Santos AJ. Metástasis esternal por hepatocarcinoma. An Med Interna (Madrid) 2002; 19: 490

5. Uemura A, Fujimoto H, Yasuda S, et al. Transcatheter arterial embolization for bone metastases from hepatocellular carcinoma. Eur Radiol 2001; 11: 1457-62.

6. Kaizu T, Karasawa K, Tanaka Y, et al. Radiotherapy for osseous metastases from hepatocellular carcinoma: a retrospective study of 57 patients. Am J Gastroenterol 1998; 93: 2167-71.

\section{Pancreatitis aguda inducida por carbamacepina}

\section{Sr. Director:}

La pancreatitis inducida por fármacos es un efecto secundario bien conocido de algunos medicamentos, siendo dudoso con otros. Así, la pancreatitis inducida por carbamacepina (CBZ) es un efecto adverso no descrito en su ficha técnica y del que tan sólo se conocen cinco casos en la literatura médica (2-6). Presentamos un caso de pancreatitis aguda en el que se plantea la toma de carbamacepina, como probable factor etiológico y realizamos una revisión de la literatura. 
Mujer de 73 años de edad, sometida en 1993 a tumorectomía amplia y vaciado axilar, por adenocarcinoma de mama derecha, sin tratamiento quimio-radioterápico y con revisiones posteriores sin evidencia de recidiva. No bebedora de alcohol ni fumadora, mantenía tratamiento con loracepam, $1 \mathrm{mg}$ al día desde hacía al menos un año. Un mes antes de su ingreso, presentó neuralgia postherpética en miembro superior derecho, por lo que se le prescribió CBZ, $300 \mathrm{mg}$ al día. En este contexto, acudió a urgencias al presentar, de forma brusca, dolor abdominal intenso en hipocondrio izquierdo irradiado al resto del abdomen, junto con vómitos biliosos. En la exploración física general, no se apreciaron hallazgos de interés salvo dolor epigástrico sin defensa muscular. Analítica al ingreso: Hemograma: leucocitos: 14 x 109/L, con neutrofilia, hemoglobina: $12,7 \mathrm{~g} / \mathrm{dL}$, hematocrito: $36,9 \%$, plaquetas: $248 \mathrm{x}$ $10^{9} / \mathrm{L}$, tiempos de coagulación normales. Bioquímica de urgencias al ingreso: glucemia: $152 \mathrm{mg} / \mathrm{dL}$, calcio total: 8,50 $\mathrm{mg} / \mathrm{dL}$, amilasa: $5.227 \mathrm{UI} / \mathrm{L}, \mathrm{LDH}: 535 \mathrm{U} / \mathrm{L}$, sodio, potasio, urea y creatinina normales. Orina: amilasuria: $66.900 \mathrm{U} / \mathrm{L}$. Analítica de control a las 48 horas: Hemograma: hematocrito: 35,2\%. Bilirrubina total: 0,66 mg/dL, GPT: $41 \mathrm{U} / \mathrm{L}, \mathrm{GOT}: 25$ U/L, GGT: 5.227 U/L, FA: 119 U/L, amilasa: 767 U/L, lipasa: $272 \mathrm{U} / \mathrm{L}, \mathrm{LDH}$ : $545 \mathrm{U} / \mathrm{L}$, calcio: 7,75 mg/dL, glucosa, sodio, potasio, triglicéridos y colesterol normales. Balance hídrico equilibrado. Radiografías de tórax y simple de abdomen: pequeño derrame pleural izquierdo. Ecografía abdominal: vesícula biliar ligeramente distendida, sin litiasis en su interior, vía biliar y páncreas normal. TAC de abdomen: páncreas de tamaño normal con bordes desflecados, líquido libre peripancreático, perihepático y pararrenal anterior izquierdo. Vesícula distendida sin imágenes en su interior y derrame pleural bilateral. Colangiorresonancia: vesícula vías biliares normales, páncreas edematoso de forma difusa con pseudoquiste en cola. La evolución inicial fue tórpida, desarrollando fibrilación auricular e intenso dolor abdominal, que precisaron dieta absoluta(se retiró la CBZ), nutrición parenteral y tratamiento antiarrítmico intravenoso, consiguiendo en 15 días la remisión completa clínico-analítica del cuadro y la reversión a ritmo sinusal. El control analgésico de la lesión herpética se consiguió con metamizol.

Nos encontramos ante un cuadro de pancreatitis aguda grave, sin un claro factor desencadenante, salvo la relación cronológica entre la toma de CBZ y el desarrollo de la pancreatitis. Aplicamos el algoritmo de imputación de efectos secundarios por fármacos de Naranjo (7), considerando la reacción adversa probable. No se reintrodujo la CBZ por no considerarlo beneficioso ni ético. Realizamos una búsqueda en Internet, a través de medline sin límites y usando como palabras clave: carbamazepine, pancreatitis, encontrando cinco casos (2-6) (Tabla I). No se ha encontrado, en una búsqueda paralela, relación entre infección herpética y pancreatitis

No obstante, dado que este efecto secundario es excepcional, que las pruebas complementarias no tienen una sensibilidad y especificidad del $100 \%$ y que hasta el $50 \%$ de las pancreatitis idiopáticas, se diagnostican de origen litiásico tras dos años de seguimiento, establecimos un control evolutivo por consultas externas. Así, seis meses más tarde, la paciente reingresó con un nuevo cuadro de pancreatitis aguda, objetivándose en la ecografía litiasis biliar y vía biliar distendida. Si bien finalmente tan sólo podemos establecer la relación de pancreatitis por CBZ como probable en el diagnóstico diferencial, defendemos la importancia de analizar el posible papel de los distintos fármacos que tome el paciente, mediante la aplicación de algoritmos de imputación de efectos secundarios, existan o no causas típicamente relacionadas con el desarrollo de pancreatitis.

\section{A. Benavente Fernández, O. Barakat Shrem¹, I. Ibáñez Godoy $^{2}$, M. J. Fernández Pérez, M. A. Bolívar Raya ${ }^{3}$}

Servicio de Medicina Interna. ${ }^{1}$ Unidad de Cuidados Intensivos. Hospital Infanta Elena. ${ }^{2}$ Servicio de Pediatría. Hospital Juan Ramón Jiménez. ${ }^{3}$ Servicio de Farmacia Hospitalaria. Hospital Infanta Elena. Huelva

1. Consejo General de Colegios Oficiales de Farmacéuticos. Catálogo de Especialidades Farmacéuticas, 2002. p. 1839-1841.

2. Soman M, Swenson C. A possible case of carbamacepine-induced pancreatitis. Drug Intelligence and Clinical Pharmacy 1985; 19: 925926.

3. Pezzilli R, Billi P, Melandri R, Broccoli PL, Fontana G. Anticonvulsivant-induced chronic pancreatitis. A case report. Ital J Gastroenterol 1992; 24: 245-246.

4. Javaloyas M, Casasin T. Acute pancreatitis due to carbamazepine in a patients with AIDS. Med Clin (Barc) 1998; 110: 437.

5. Forte A, Gallinaro L, Montesano G, Turano R, Bertagni A, Illuminati G. A possible case of carbamazepine induced pancreatitis. Riv Eur Sci Med Farmacol 1996; 18: 187-9.

6. Tsao CY, Wright FS. Acute chemical pancreatitis associated with carbamazepine intoxication. Epilepsia 1993; 34: 174-6.

7. Naranjo CA, Busto U, Sellers EM, Sandor P, Ruiz I, Roberts EA, Janacek E, Domeq C, Greenblatt DJ. A method for estimating the probabiliti of adverse drug reactions. Clin Pharmacol Ther 1981; 31: 30, 239-245.

8. Laporte JR, Lience E. Información mínima que deben contener las publicaciones sobre sospechas de reacciones adversas a medicamentos. Med Clin (Barc) 1991; 97: 56-57.

TABLA I

REVISIÓN DE LOS CASOS DE PANCREATITIS AGUDA RELACIONADOS CON CBZ

\begin{tabular}{|c|c|c|c|c|c|c|}
\hline Autores & $N^{0}$ casos & Sexo & Edad & Dosis & $\begin{array}{l}\text { Tiempo } \\
\text { de toma }\end{array}$ & $\begin{array}{c}\text { Causa de } \\
\text { prescripción }\end{array}$ \\
\hline Soman & 1 & $M$ & $73 a$ & 200 mg/día & 4 semanas & $\begin{array}{c}\text { Crisis parciales } \\
\text { complejas }\end{array}$ \\
\hline Pezzilli & 1 & V & $25 a$ & 1200 mg/dia & 10 años & $\begin{array}{c}\text { Epilepsia } \\
\text { post-traumática }\end{array}$ \\
\hline Javaloyas & 1 & V & $27 a$ & 600 mg/día & 72 horas & $\begin{array}{c}\text { Polineuropatía } \\
\text { sensitivomotora en VIH }\end{array}$ \\
\hline Forte & 1 & & & Información no disponible & & $\begin{array}{l}\text { Epilepsia postraumática } \\
\text { petit mal }\end{array}$ \\
\hline Tsao & 1 & V & $5 a$ & Desconocida & ¿Horas? & Intoxicación \\
\hline
\end{tabular}




\section{Meningoencefalitis por virus herpes simple tipo 6 en adulto inmunocompetente}

\section{Sr. Director:}

El grupo de los herpesvirus se conforma de siete virus, pudiendo afectar todos ellos al sistema nervioso central (SNC) en mayor o menor grado, siendo la primoinfección inusual en un huesped inmunocompetente (1), y siendo aún más infrecuente si se trata del virus del herpes tipo 6 (hasta 1998 sólo habían sido 17 los casos publicados de meningitis y encefalitis por VHS-6 en paciente adulto inmunocompetente) (2). Presentamos aquí el caso de un paciente que fue ingresado en nuestra unidad por un cuadro de meningoencefalitis, posteriormente filiado como secundario a infección por VHS-6, que cursó con un desenlace fatal.

Paciente de 29 años de edad, antecedentes personales de nefrolitiasis e hipercolesterolemia, que ingresa en el servicio de urgencias de nuestro hospital con una clínica de 5 dias de evolución de fiebre alta termometrada $\left(38-39{ }^{\circ} \mathrm{C}\right)$, acompañada de escalofríos, artromialgias y erupción exantemática en ambas manos y abdomen. A su ingreso la erupción había desaparecido, la faringe se encontraba enrrojecida, y existía dolor a la palpación profunda en epigastrio. En el plazo de veinticuatro horas desarrolló cuadro de inestabilidad hemodinámica ingresando en nuestra Unidad de Medicina Intensiva en situación de shock: presión arterial imperceptible, frecuencia cardiaca de 140 l.p.m, sinusal, livideces generalizadas, hipotérmico, mal perfundido e hidratado, con un GCS (Glasgow Coma Scale) de 15 puntos con paraparesia fláccida. En la analítica destacaba la existencia de una trombocitopenia intensa (16.000 plaquetas), 16x109 leucocitos (95\% de PMN), fibrinogeno de $325 \mathrm{mg} / \mathrm{dl}$. Con el diagnóstico inicial de sepsis de origen desconocido se inició terapia antibiótica empírica según protocolo de la unidad, requiriendo de apoyo inotrópico (dopamina y noradrenalina), y desarrollando un grave compromiso respiratorio.

Poco despues presentó cuadro de convulsión tónica generalizada con mordedura de lengua, requiriendo sedación con benzodiacepinas, intubación orotraqueal y conexión a ventilación mecánica. No se practicó inicialmente punción lumbar ante la trombopenia severa (con la posibilidad de originar complicaciones hemorrágicas en raquis). La T.A.C (tomografía axial computorizada) craneal mostró edema cerebral intenso, por lo que añadió al tratamiento corticoterapia a expensas de dexametasona (4 mg i.v./6h) así como medidas habituales dirigidas contra el edema cerebral. Entre la analítica extraída, el virus de la inmunodeficiencia adquirida, antígeno de legionella y neumococo, antígenos heterófilos de mononucleosis infecciosa resultaron negativos, así como numerosos hemocultivos, urocultivos y cultivos de secreciones. Los factores del complemento tambien se encontraban dentro de la normalidad.

Realizada finalmente punción lumbar al tercer día del ingreso, una vez corregida parcialmente la trombocitopenia mediante transfusiones de plaquetas, el líquido era intensamente xantocrómico, con 33 leucocitos (98\% PMN, 2\% mononucleares), 264 hematies, glucorraquia de $33 \mathrm{mg} / \mathrm{dl}(45-75 \mathrm{mg} / \mathrm{dl})$, proteinorraquia de $705 \mathrm{mg} / \mathrm{dl}(15-45 \mathrm{mg} / \mathrm{dl}), \mathrm{LDH} 14356 \mathrm{U} / \mathrm{l}$, en la tinción de Gram no se observaban gérmenes, los antígenos bacterianos así como el cultivo resultaron negativos. Los cultivos de bacterias, hongos, mycobacterias y virus resultaron negativos. Remitida muestra de líquido cefalorraquídeo para estudio de P.C.R (reacción de cadena de polimerasa) en laboratorio de referencia sólo se amplificó la existencia de virus herpes humano tipo 6 como único hallazgo microbiológico.

La evolución fue tórpida, con afectación multiorgánica progresiva, siendo finalmente exitus a los 13 dias de su ingreso en nuestra unidad en situación de muerte encefálica clínica.
La primera descripción de la encefalitis por VHS-6 fue hecha por Ishiguro y cols. en 1990 (3) en un niño de 10 meses. Aunque con posterioridad se han descrito encefalitis en niños inmunocompetentes, en adultos ha sido escasamente descrito. En la serie publicada por Torre y cols. en el año 1998 (2), empleando el Medline como método de busqueda bibliográfica, entre los años 1966 y el 1997, sólo fueron encontrados 17 casos de meningitis y/o encefalitis en adulto inmunocompetente.

La seropositividad se ve incrementada con la edad, lo cual indica que la mayoría de la población está expuesta al virus en la infancia. Luppi y cols. (4) detectaron DNA del VHS-6 por PCR en tejidos cerebrales de pacientes sin clínica neurológica y con cerebros normales en un alto porcentaje de pacientes. Sin embargo, este aislamiento no debe indicar infección o patogenicidad, pudiendose pues suponer una "latencia" del genoma viral en reservorios celulares, los cuales incluyen el cerebral (5). Se postula que el SNC puede ser el lugar de persistencia del HHV-6 como estado latente tras la resolución de la primoinfección (2): la infección primaria en el adulto es relativamente rara, mientras que la reactivación en un paciente inmunocomprometido es relativamente más frecuente.

La forma en como el virus puede llegar a afectar el SNC es diversa: afectación directa, bien de las células o de las meninges (originando encefalitis o meningitis según los casos), o desarrollando una respuesta autoinmune hacia antígenos de la mielina. La forma en como llegan los virus al SNC difiere: a raiz de una viremia (replicación del virus en la puerta de entrada: mucosa respiratoria, digestiva, etc.), a través de un acceso neural directo (a través de un nervio periférico como ocurre en el caso de los virus del grupo herpes desde la mucosa olfatoria via nervio olfatorio, o desde el ganglio trigeminal, lugares donde se encuentra en estado latente, por vía retrograda del nervio trigémino a la fosa cerebral anterior y media).

En relación con el diagnóstico de la infección en $\mathrm{SNC}$, La PCR presenta una alta sensibilidad y especificidad en la detección del agente etiológico, que puede llegar a ser del 98 y $94 \%$ respectivamente (6). Teóricamente la PCR puede detectar la presencia de genoma viral y puede realizarse en menos de 5 horas.

\section{A. Córdoba López, I. Bueno Álvarez-Arenas', J. Monterrubio Villar, J. Sánchez Castañón ${ }^{2}$}

Unidad de Cuidados Intensivos. ${ }^{1}$ Servicios de Medicina Familiar y Comunitaria y de ${ }^{2}$ Microbiología. Hospital Don Benito-Villanueva. Badajoz

1. Arroyo HA, Bologna R. Encefalitis viral. Rev Neurol 1997; 25 (142): 912-919.

2. Torre D, Speranza F,. Martegani R, Ferrante P, Omodeo-Zorini E, Mancuso R, Fiori GP. Meningoencephalitis Caused by Human Herpesvirus-6 in an Immunocompetent Adult Patient: Case report and Review of the Literature. Infection 1998; 26: 402-404.

3. Ishiguro N, Yamada S, Takahashi T, Takahashi Y, Togashi T, Okuno T, Yamanishi K. Meningoencephalitis associated with HHV-6 related exanthum subitum. Acta Pediatr Scand 1990; 79: 987-989.

4. Luppi M, Barozzi P, Maiorana A, Marasca R, Torelli G. Human herpesvirus 6 infection in normal human brain tissue. J Infect Dis 1994; 169: 943-944.

5. Caserta MT, Hall CB, Schnabel K, Mc Intire K, Long C, Constanzo M, Dewhurst S, Insel R, Epstein LG. Neuroinvasion and persistence of human herpesvirus 6 in children. J Infect Dis 1994; 170: 1586-1589.

6. Lakeman FD, Whitley RJ, National Institutes of Allergy and Infectious Diseases Collaborative Antivitral Study Group. Diagnosis of herpes simplex encephalitis: application of polymerase chain reaction to cerobrospinal fluid from brain-biopsied patients and correlation with disease. J Infect Dis 1995; 171: 857-63. 
Insuficiencia respiratoria aguda que precisa ventilación mecánica: debut de una miastenia gravis

\section{Sr. Director:}

La miastenia gravis es una enfermedad autoinmune de la unión neuromuscular que se caracteriza por debilidad fluctuante, empeora con la actividad física y tiende a la recuperación mediante el reposo o la utilización de anticolinesterásicos. Sus manifestaciones clínicas son variables y dependen de los grupos musculares afectados, estas condiciones propician que se cometan errores diagnósticos que retardan el inicio del tratamiento, de ahí que diagnosticarla de forma precoz y prevenir la complicaciones derivadas de la debilidad muscular como la insuficiencia respiratoria es de vital importancia.

Mujer de 36 años que ingresa en la UCI por insuficiencia respiratoria aguda hipoxémica-hipercápnica. Antecedentes de: crisis epilépticas en tratamiento con carbamacepina y fenómeno de Raynaud. Acude por disnea de reposo acompañada de tos y expectoración, además refiere sindrome general de 3 meses de evolución. Hemograma, bioquímica y coagulación normales y en la gasometría: $\mathrm{pO}_{2}$ : $69 \mathrm{mmHg}, \mathrm{pCO}_{2}$ : $42 \mathrm{mmHg}, \mathrm{pH}: 7,38$ y Bicarbonato: 25, Rx de tórax: opacidad mal definida basal izquierda, ECG: taquicardia sinusal y sobrecarga derecha. Ingresa con el diagnóstico de insuficiencia respiratoria secundaria a infección y/o TEP. Se solicitó gammagrafía ventilacion-perfusión: estudio de baja probabilidad diagnóstica para embolismo. En una gasometría posterior presenta: $\mathrm{pO}_{2}: 99 \mathrm{mmHg}, \mathrm{pCO}_{2}: 69$ mmHg, pH: 7,22 con $\mathrm{FiO}_{2}$ al $30 \%$. Se somete a ventilación no invasiva con buena tolerancia y mejoría inicial notable. A las 48 horas presenta desadaptación a la Bipap, así como empeoramiento gasométrico con acidosis respiratoria grave $(\mathrm{pH}: 7,18)$ por lo que se decide ingreso en nuestra unidad: consciente con ligera tendencia al sueño, sin datos de focalidad neurológica, debilidad muscular generalizada, dificultad para hablar, ptosis palpebral bilateral, salivación intensa, bradipnea, ROTs y pruebas cerebelosas normales. Auscultación: hipoventilación bilateral acusada. Dada la situación respiratoria se procede a intubacion orotraqueal y conexión a ventilación mecánica controlada. Ante la sospecha clínica de posible crisis de miastenia gravis, se procede a realizartest del Tensilón (10 mg de edrofonio), obteniendose una moderada mejoría clínica, por lo que se inicia tratamiento con dosis bajas de piridostigmina (mestinon $60 \mathrm{mg} / 4$ horas por SNG). y tras un primer intento de extubación fracasado, se incrementó la dosis a $75 \mathrm{mg} / 4$ horas pudiendose extubar sin incidencias al $5^{\circ}$ día de su ingreso en la unidad. Se realizó TAC torácico no evidenciándose masas ni alteración tímica a dicho nivel. En el estudio inmunológico: Anti-Scl 70: negativo, anticuerpos ANA con método IFI: positivos (título 1/320) con patrón moteado, ANCAS: negativo y anticuerpos anti-receptor de acetilcolina en suero: $6,81 \mathrm{nmol} / \mathrm{L}(\mathrm{N}<0,2)$. Pruebas de función tiroidea normales y en el estudio electromiográfico ( músculo frontalis ): se observa un acusado incremento del "jitter" hallazgos compatibles con transtorno de la unión neuromuscular. Se sometió a timectomía que demostró hiperplasia folicular tímica.

La miastenia gravis es una enfermedad autoinmune caracterizada por fatigabilidad y debilidad muscular fluctuante, con variaciones horarias o estacionales, empeora con el ejercicio y mejora con el reposo, pudiéndose desencadenar los síntomas con los cambios térmicos, infecciones intercurrentes, la mestruación, cambios emocionales y ciertos fármacos (antibióticos como aminoglucósidos ó quinolonas, antiarritmicos, antidepresivos). Cuando se afecta la musculatura respiratoria puede producir compromiso respiratorio con insuficiencia respiratoria que requiere intubación y asistencia respiratoria como ocurrió en nuestro caso, siendo ésta y la aspiración por afectación de la muscultura faríngea, la complicaciones que pueden suponer una amenaza para la vida del paciente, de ahí la necesidad de realizar un diagnóstico precoz. La incidencia de crisis es del 10-15\% de los pacientes, siendo la causa desencadenante mas frecuente la infección respiratoria, probable desencadenante en nuestro paciente y que en determinados casos puede enmascarar ó confundirnos a la hora del diagnóstico. Ademas de la clasificación de Osserman, existe otra clasificación menos conocida pero no menos importante que es la de Compston (1), en base a la edad de comienzo y la presencia o no de timoma (Tabla I). Según esta clasificación nuestra paciente pertenecería al grupo de miastenia gravis de inicio antes de los 40 años, sin timoma, títulos altos de anticuerpos anti-acetilcolina (títulos de 6,81 nmol/l, normal: < 0,2) y con datos de hiperplasia folicular en el timo como en nuestro caso.

El diagnóstico de la mistenia gravis se fundamenta en la clínica, las pruebas farmacológicas, determinación de anticuerpos y los estudios electrofisiológicos, no existiendo un criterio unánime en cuanto el orden a seguir, estableciéndose por la rapidez en la obtención de resultados de las distintas pruebas y en nuestro caso, dada la rapidez del test de Tensilón ${ }^{\circledast}$ con respecto a la determinación de anticuerpos (necesidad de enviar la muestra a otro centro hospitalario) optamos por dicha prueba farmacológica. En cuanto a las pruebas farmacológicas, de los mas utilizadas: piridostigmina, neostigmina y edrofonio, será ésta última la que se utiliza como prueba diagnóstica (prueba del Tensilón ${ }^{\circledR}$ ) con más frecuencia en la clínica; dicha prueba no es específica de la miastenia (2) (falsos positivos como: síndrome de Eaton-Lambert, miositis, sdr. de Guillain-Barré o esclerosis lateral amiotrófica), pero con una alta sensibilidad.

\section{TABLA I}

CLASIFICACIÓN DE COMPSTON

\begin{tabular}{llll}
\hline & $\begin{array}{l}\text { Alteraciones } \\
\text { tímicas }\end{array}$ & $\begin{array}{l}\text { Título de ACS } \\
\text { acetilcolina }\end{array}$ & Sexo \\
\hline $\begin{array}{c}\text { Miastenia gravis } \\
\text { con timoma }\end{array}$ & Timoma & Intermedio & $=$ \\
$\begin{array}{c}\text { Miastenia gravis } \\
\text { sin timoma antes }\end{array}$ & $\begin{array}{l}\text { Hiperplasia } \\
\text { témica }\end{array}$ & Alto 40 años & Mujer \\
$\begin{array}{c}\text { Miastenia gravis } \\
\text { sin timoma después } \\
\text { de los } 40 \text { años }\end{array}$ & $\begin{array}{l}\text { Atrofia } \\
\text { tímica }\end{array}$ & Bajos & Varón \\
\hline
\end{tabular}

La determinación de anticuerpos antireceptor de acetilcolina es altamente específica de tal manera que si el resultado es positivo se puede establecer con seguridad el diagnóstico (3).

En cuanto a la valoración electrofisiológica se incluye la estimulación nerviosa repetitiva (Jolly) y la electromiografía de fibra única ó simple. Aunque la primera es quizá el método electrofisiológico mas frecuentemente utilizado, es la electromiografía de fibra única o aislada, que fué la realizada en nuestro caso, una prueba mas sensible que la primera, ya que casi el $100 \%$ de los casos es positiva incluso en formas exlusivamente oculares, siendo para muchos autores el estudio de elección en el diagnóstico de la miastenia gravis, específicamente cuando los anticuerpos y la prueba de estimulación repetitiva (Jolly) son negativos (4). Es curioso observar como la miastenia gravis puede asociarse con otras afecciones especialmente autoinmunes y en el caso que nosotros presentamos podemos observar dos datos a favor de esta posible asociación, por un lado los antecedentes de fenómeno de 
Raynaud y por el otro un título de anticuerpos ANA con patrón moteado positivos con un título 1/320. Mención especial merece la relación entre miastenia y las alteraciones del timo, aproximadamente el $75 \%$ de los pacientes con miastenia tienen alteraciones tímicas y de estos en un $65 \%$ el timo presenta hiperplasia tímica como sucedió en nuestro caso. En referencia al tratamiento médico únicamente reseñar que nuestra paciente fué tratada con éxito mediante piridostigmina, siendo necesario inicialmente un reajuste de la dosis que nos permitió la desconexión de la ventilación mecánica y extubación, ya que no existe una dosis estandar para estos fármacos, pudiendo variar en un mismo paciente de unos períodos a otros, no precisando nuestro caso de tratamiento inmunosupresor durante la fase aguda (5).

\section{J. L. Martínez Melgar, A. Baloira Villar ${ }^{1}$, J. C. Rodríguez García $^{2}$}

Unidad de Cuidados Críticos, Servicios de 'Neumología y de ${ }^{2}$ Medicina Interna. Hospital de Montecelo. Sergas. Pontevedra

1. Compston DAS, Vincent A, Newson-Davis J. Clinical, pathological, HLA antigen and inmunological evidence for disease heterogenety in myasthenia gravis. Brain 1980; 103: 579-601.

2. Oh SJ, Kim DE, KurnoglnR, Bradley RJ. Diagnostic sensitivity of the laboratorytests in myasthenia gravis. Muscle Nerve 1992; 15: 720-724.

3. Massey J. Acquired myasthenia gravis. Neurol Clin 1997; 15: 577-95.

4. Lennon V. serologic profileof myasthenia gravis and distinction from the Lambert-Eaton myasthenic syndrome. Neurology 1997; 48: 23-27.

5. Drachman DB. Myasthenia gravis. N Engl J Med 1994; 330: 1797-1810.

\section{Piomiositis en músculo esternocleidomastoideo}

\section{Sr. Director:}

La piomiositis es una infección bacteriana aguda que ocurre en el músculo estriado y que suele dar lugar a la formación de abscesos. El lugar de asiento más habitual es sobre la musculatura larga de extremidades inferiores, siendo la musculatura cervical excepcional. El patógeno etiológico más frecuente es Staphilococcus aureus $(1,2)$. Se describe en climas tropicales y en nuestro medio se asocia a pacientes con alguna enfermedad de base $(3,4)$. Creemos de interés el presentar este nuevo caso de piomiositis causado por Staphilococcus aureus pues la afectación sobre el músculo esternocleido mastoideo es una localización excepcional.

Paciente de 75 años de edad, con antecedentes de cirrosis hepática y pancreatitis crónica de etiología etílica, fumador con criterios clínicos de bronquitis crónica y alérgico a penicilinas. Había estado ingresado 5 días atrás por una primera descompensación ascítica que fue tratada con paracentesis evacuadoras, evolucionando sin más complicaciones que una ligera flebitis en el brazo donde había tenido implantado un catéter periférico. El día de su ingreso es traído a urgencias con un cuadro de obnubilación y fiebre, manifestando dolor en región supraclavicular izquierda. La exploración física mostró a un paciente con signos de síndrome séptico con una temperatura de $39{ }^{\circ} \mathrm{C}$, hipotenso y mal prefundido que presentaba una discreta tumoración cervical izquierda que se correspondía con el músculo esternocleidomastoideo y una movilidad cervical lateral limitada. Habían signos de una flebitis en resolución en el antebrazo izquierdo. El abdomen mostraba una discreta ascitis sin signos de peritonismo y el resto fue normal. El hemograma mostró una leucocitosis con desviación izquierda (12.000 leucocitos con un 80\% de neutrófilos), $\mathrm{Hb}$ de $9,1 \mathrm{~g} / \mathrm{dl}$ y unas plaquetas de $96.000 / \mathrm{mm}^{3}$ y los principales parámetros bioquímicos fueron: VSG $40 \mathrm{~mm} 1^{\text {a }}$ hora, PCR $95 \mathrm{mg} / \mathrm{l}$, urea $188 \mathrm{mg} / \mathrm{dl}$, creatinina $6,1 \mathrm{mg} / \mathrm{dl}$, bilirrubina total $6,6 \mathrm{mg} / \mathrm{dl}$ (con una bilirrubina directa 5,6 mg/dl), Na $125 \mathrm{mEq} / \mathrm{l}, \mathrm{K}$ 4,7 mEq/l, GOT 73UI/l, F alcalina 380 UI/l, GGT 63UI/l y albúmina $1,6 \mathrm{~g} / \mathrm{dl}$. El estudio del líquido ascítico reveló que se trataba de un trasudado con cultivos y citología de células malignas negativas. Una exploración radiológica de región cervical y de tórax no ofreció ningún dato relevante. Se le practicó un TAC cervical sin contraste (dada la insuficiencia renal del enfermo) que puso de manifiesto un aumento de grosor del músculo esternocleidomastoideo izquierdo con imágenes hipodensas compatibles con abscesos (Fig. 1). Se aprecian además numerosas adenopatías que siguen los vasos laterocervicales izquierdos. El ecocardiograma no mostró signos de endocarditis. Ante el estado del enfermo se había iniciado tratamiento con levofloxacino y teicoplanina IV, pero al recibirse 72 horas más tarde el resultado de los hemocultivos (Staphilococcus aureus positivos 3/3) decidimos suspender el primero. Posteriormente, se solicitó punción y drenaje de los abscesos al servicio de ORL, obteniendo un líquido de aspecto purulento pero en el que no creció germen alguno. El estado del paciente fue mejorando paulatinamente, quedando apirético, solucionándose su fallo renal y desapareciendo la tumefacción cervical, hasta su completa resolución.

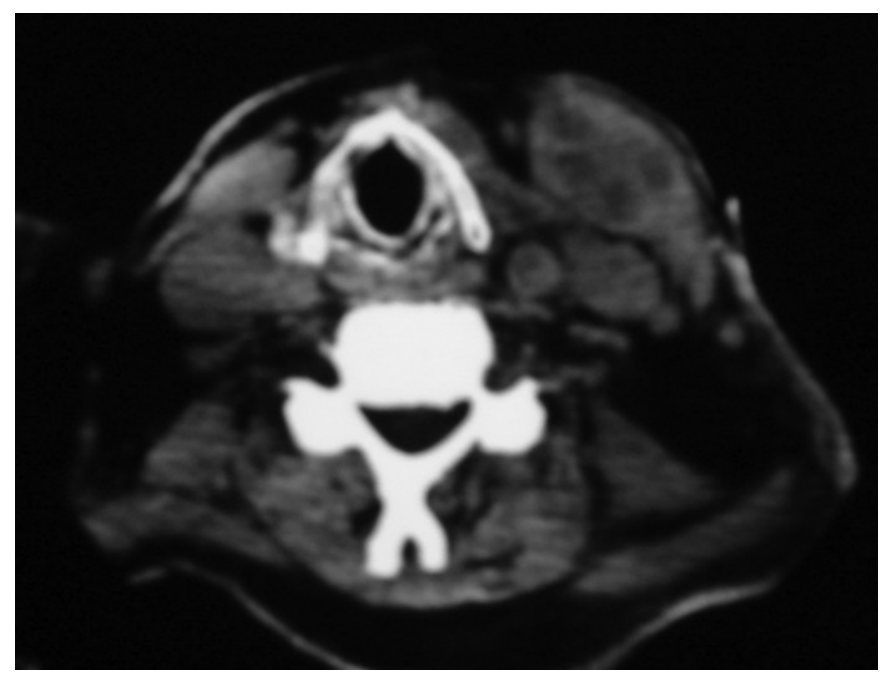

Fig. 1. TAC cervical.

La piomiositis o infección muscular primaria es una infección poco habitual limitando su descripción hasta hace unas décadas a las regiones tropicales (1). Se localiza con mayor frecuencia en la musculatura larga de las extremidades (glúteos, muslos y gemelos) seguido de tronco y en abdomen. El patógeno aislado más frecuentemente es el Staphilococcus aureus en más del $80 \%$ de los casos, aunque también se hallan estreptococos de los grupos A, B, C y G, otros gram positivos y Enterobacterias $(2,3,5)$. La patogenia implica una bacteriemia de cualquier origen que habitualmente es asintomática y transitoria, en nuestro caso probablemente sea debida a la flebitis por una vía periférica que desarrolló sobre el antebrazo izquierdo en los días previos, habiéndose invocado también la presencia de un traumatismo muscular previo, infecciones parasitarias o virales y déficit nutricionales o vitamínicos (estos últimos frecuentes en las formas tropicales) $(1,3)$. En nuestro medio las causas predisponentes más habituales son la diabetes mellitus, las hepatopatías crónicas (que era el caso del paciente), terapia esteroidea o inmunosupresora, las infecciones por el virus de la inmunodeficiencia y las leucemias $(3,5)$. 
Las pruebas de laboratorio suelen poner de manifiesto elevación de los reactantes de fase aguda, leucocitosis izquierda, aumento de VSG y PCR, etc., siendo con frecuencia normales los enzimas musculares (1). Para el diagnóstico de localización pueden usarse distintas técnicas de imagen, la eco, la resonancia nuclear magnética que está considerada como la más útil en fases iniciales y el TAC (como en nuestro caso), que muestra imágenes de baja densidad que se corresponden con la zona purulenta y que tras la administración de contraste presentan captación periférica anular Cuando se sospecha la afectación simultánea de varios músculos puede ser de utilidad la gammagrafía con galio 67 (6). Habitualmente el tratamiento resolutivo pasa por combinar terapia antibiótica con técnicas quirúrgicas ya sea desbridamiento ya sea punción-aspiración ecográficamente guiada. No obstante algunos casos, puede ser suficiente el uso único de antibioterapia (7).

\section{J. V. Calduch Broseta, M. M. Segarra Soria, H. Briceño, C. Galván}

Servicio de Medicina Interna. Hospital General de Elda. Alicante

1. Chediozi LC. Pyomiositis. Review of 205 cases in 112 patients. Am J Surg 1979; 137: 255-259.

2. Recio FJ, Díaz M, Dastis C, Pajares L. Piomiositis del esternocleidomastoideo por Staphylococcus aureus. An Med Interna (Madrid) 1993; 10: 153-154.

3. Gómez-Reino JJ, Aznar JJ, Pablos JL, Díaz-Gonzalez F, Laffon A. Nontropical piomiositis in adults. Semin Artritis Rheum 1994; 23: 396-405.

4. Clinical characteristics of Staphylococcal pyomyositis. Fan HC, Lo WT, Chu ML, Wang CC. J Microbiol Immunol Infect 2002; 35 (2): 121-4.

5. Giménez M, Sopena N, Iñado B, Cardona PJ, Pedro-Bonet PL, Coroleu $\mathrm{W}$ et al. Infecciones invasivas por Streptococcus agalactiae en un hospital general universitario en un plazo de 10 años. Enferm Infecc Microbiol Clin 1996; 14; 300-303.

6. Magnetic resonance imaging of pyomyositis in 43 cases. Soler R, Rodrí guez E, Aguilera C, Fernández R. Eur J Radiol 2000; 35 (1): 59-64.

7. Jiménez-Mejías ME, Lozano L, Alfaro-García MJ, Fernández-López A, Jiménez C, Cañas E, Pachón-Díaz J. Piomiositis por Staphilococcus aureus. Med Clin (Barc) 1992; 99: 201-205.

\section{Megaesófago y fibrosis pulmonar}

\section{Sr. Director:}

La acalasia es un trastorno esofágico, consistente en la ausencia de peristaltismo y la existencia de una relajación incompleta del esfínter esofágico inferior en respuesta a la deglución, cuya presión basal está con frecuencia elevada. Estas alteraciones motoras producen una obstrucción funcional al tránsito esofágico que se traduce clínicamente en la aparición de disfagia, dolor torácico, pirosis y, con menor frecuencia, regurgitación del material deglutido y retenido en el esófago. La incidencia anual es de 1 caso cada 100.000-250.000 personas, sin predominio de sexos, predominando en la $3^{\mathrm{a}}-5^{\mathrm{a}}$ décadas de la vida. La causa permanece desconocida y debe ser diferenciada de la pseudoacalasia (infiltración tumoral del cardias). El método diagnóstico principal es la manometría esofágica. El tratamiento es paliativo y consite en fármacos, endoscopia o cirugía, la elección depende de las características de cada paciente.

Mujer de 65 años de edad, sin antecedentes patológicos de interés, no refería hábitos tóxicos, ni alergias medicamentosas conocidas, ni tampoco antecedentes epidemiológicos significativos y no consumía fármacos de forma habitual. Entre los antecedentes patológicos familiares destacan la muerte del padre por hepatocarcinoma y la de un hermano por neoplasia digestiva. Veinte horas antes del ingreso, comienza con dolor epigástrico continuo, náuseas, vómitos alimentarios y abundante salivación. Así mismo refería dolor en región lumbar que relacionaba con los esfuerzos para vomitar y tos irritativa de predominio nocturno desde hacía años. En ningún momento refirió disfagia. En la exploración física la paciente presentaba hábito asténico, discreta cianosis acra, TA $120 / 70 \mathrm{~mm}$ de $\mathrm{Hg}, \mathrm{T}^{\mathrm{a}} 37,5^{\circ} \mathrm{C}$, taquipnea $\left(24 \mathrm{x}^{\prime}\right)$, pulso regular a $80 \mathrm{lpm}$, chapetas malares, eritema pernio en dorso de la nariz. Ingurgitación yugular bilateral y abundante circulación colateral en parte anterior del tórax. En región cervical se palpaba un aumento del tiroides a expensas sobre todo del lóbulo derecho. La auscultación pulmonar mostraba una disminución generalizada del murmullo vesicular con estertores crepitantes en ambas bases pulmonares. La auscultación cardíaca destacaba un refuerzo del segundo tono cardiaco. El resto de exploración resultaba anodino. En las pruebas de laboratorio. síndrome de la T3 baja e insuficiencia respiratoria parcial (pO2 54,6 mm de $\mathrm{Hg}$, Sat $\mathrm{O} 278,8 \%$ ), el resto de analítica, incluyendo estudio de autoinmunidad, marcadores tumorales, inmunoglobulinas fueron normales. La radiografía de tórax mostró un megaesófago con nivel hidroaéreo en región cervical y desaparición de la cámara gástrica, así como un patrón en vidrio deslustrado bilateral que afectaba fundamentalmente a campos posteriores. Las pruebas funcionales respiratorias demostraban una disminución del FEF $25 / 75 \%$, los demás parámetros espirográficos resultaron normales, incluyendo la DLCO. El estudio baritado esofagogastroduodenal gran dilatación del cuerpo esofágico con afilamiento distal. La gastroscopia se informó como esófago dilatado con retención moderada de alimento, la exploración del fundus resultó normal. La TAC torácica informó de una marcada dilatación esofágica y aumento de densidad pulmonar bilateral "vidrio deslustrado" que afecta fundamentalmente a campos posteriores. La manometría esofágica puso de manifiesto la aperistalsis del cuerpo esofágico (ondas simultáneas de 10-15 mm de $\mathrm{Hg}$ ). El esfínter esofágico inferior no pudo ser estudiado por no poder pasar la sonda. Se realizó broncoscopia que se informó como normal, cepillado y BAL que dieron lugar a salida de contenido que recordaba alimento digerido. Biopsia pleural que fue informada por anatomía patológica como material insuficiente. Se remitieron muestras del BAL para citometría de flujo, citología y estudio microbiológico, siendo los resultados obtenidos compatibles con infiltrado inflamatorio inespecífico.

Iniciamos tratamiento con medidas posturales, oxigenoterapia y antagonistas del calcio a dosis de $10 \mathrm{mg}$ por vía sublingual 30 minutos antes de cada comida, con lo cual desapareció la tos nocturna y mejoró el estado de nutrición de la paciente. Cuatro semanas más tarde iniciamos tratamiento definitivo mediante dilatación endoscópica, sin complicaciones inmediatas, encontrándose actualmente asintomática. Diagnóstico: Acalasia idiopática. Fibrosis pulmonar bilateral secundaria.

La etiología del cuadro es desconocida, aunque se han propuesto múltiples agentes (infecciosos, genéticos, autoinmunes). El diagnóstico del cuadro se basa en un alto índice de sospecha clínica y exclusión de otras lesiones que podrían dar lugar a una seudoacalasia, para ello nos ayudaremos de la radiología baritada, endoscopia (necesaria para el diagnóstico diferencial y obligatoria en mayores de 50 años para descartar procesos neoplásicos), isótopos, ecoendoscopia/TAC torácico (como complemento, si existen dudas en el diagnóstico diferencial, o como en este caso para estudiar las complicaciones) y la manometría esofágica (piedra angular para el diagnóstico). Es importante hacer diagnóstico diferencial con la seudoacalasia o acalasia secundaria, esta última en la mayor parte de los casos es secundaria a infiltración tumoral del esófago distal o del cardias . El tumor que más se ha asociado es el adenocarcinoma 
gástrico, pero también se ha descrito en el carcinoma escamoso metastásico, el oat cell y el linfoma. La enfermedad de Chagas, la amiloidosis y la pseudoobstrucción intestinal crónica idiopática determinan un cuadro similar a la acalasia $(1,2)$. El tratamiento de la acalasia es sólo paliativo, puede ser farmacológico, endoscópico o quirúrgico, siendo el objetivo de las distintas opciones terapeúticas conseguir disminuir la presión del esfínter esofágico inferior, y así, que el paciente pueda reincorporarse a un régimen de alimentación normal. Elegiremos una u otra opción terapéutica, dependiendo de las características de cada paciente y la accesibilidad a la misma. Aunque los resultados a largo plazo parecen ser similares, quizás las dilataciones vía endoscópica y la cirugía laparoscópica asociada a una técnica antirreflujo, sean las opciones más aceptadas, por la menor morbimortalidad y la reducción de la estancia hospitalaria (3). El tratamiento farmacológico lo utilizaríamos de forma temporal, mientras decidimos la opción terapéutica definitiva, en pacientes en que no estén indicadas otras formas más agresivas, o en aquellos casos de acalasia vigorosa en las que persiste el dolor torácico, después de haber realizado una técnica agresiva. La inyección de toxina botulínica en el esfínter esofágico inferior, dado su efecto temporal (meses), se reserva para ancianos o pacientes con otra patología de base, que dificulte las otras técnicas (4). Encontramos importante este caso, ya que en la búsqueda en medline, no hemos encontrado descrita la asociación entre acalasia y fibrosis pulmonar.

\section{A. Blanco Barrios, F. Geijo ${ }^{1}$}

Servicios de Medicina Interna y de ${ }^{2}$ Digestivo. Hospital Clínico Universitario. Salamanca

1. Sopeña Biarge F. Trastornos motores esofágicos. Medicina Clínica 1996; 7: 1-10.

2. Zárate N, Mearin F. Acalasia: nuevos conceptos de una antigua enfermedad. Gastroenterol Hepatol 1998; 21: 16-25.

3. Ponce J, Garrigues V, Pertejo, Valverde J, Gálvez C, Berenguer J. ¿Existen diferencias clínicas y en la respuesta a la dilatación neumática entre la acalasia típica y la vigorosa? Gastroenterol Hepatol 1995; 18: 315-318.

4. Ponce J. Toxina botulínica en el tratamiento de la acalasia. Gastroenterol. Hepatol. 1.998; 21: 289-293.

5. Pasricha PJ, Rai R, Ravich WJ, Hendrix TR, Kalloo AN. Botulinum toxin for achalasia: long term outcome and predictors of response. Gastroenterology 1996; 110: 1410-1415.

6. Annese V, Basciani M, Perri F, et al. Controlled trial of botulinum injection versus placebo and pneumatic dilation in achalasia. Gastroenterology 1996; 111: 1418-1424.

7. Spiess A.E, Kahrilas P.J. Treating achalasia: from whalebone to laparoscope. JAMA 1998; 280: 638-642.

8. Rosati R, Fumagalli U, Bona S, Bonavina L, Pagani M, Perachia A. Evaluating results of laparoscopic surgery for esophageal achalasia. Surg Endosc 1998; 12: 270-273.

9. Vogt D, Curet M, Pitcher D, Josloff R, Milne R.L, Zucker K. Successful treatment of esophageal achalasia with laparoscopic Heller myotomy and Toupet fundoplication. Am J Surg 1997; 174: 709-714.

\section{Morir con dignidad}

\section{Sr. Director:}

La muerte es un fenómeno natural, inevitable que nos afectará a todos, incluidos los sanitarios. Es una condición de la especie y no puede retrasarse de modo indefinido.

El personal sanitario cuando se enfrenta con la enfermedad progresiva e incurable que progresa irremediablemente hacia la muerte y por lo tanto no es posible la curación, presenta con frecuencia dudas sobre que actitudes resultaran más beneficiosas para el enfermo (1).

Los objetivos de la medicina actual deben ser evitar la muerte, pero cuando esta se presenta inevitablemente debemos conseguir que los pacientes mueran en paz (2).

Debemos evitar la práctica de medidas compatibles con la obstinación terapéutica, también llamada ensañamiento o encarnizamiento terapéutico, en un intento irracional de luchar contra la muerte próxima e inevitable (1).

Hay una tendencia por parte de las familias, muchas veces apoyada por el propio personal sanitario, intentando ocultar al enfermo información sobre su enfermedad y pronóstico y sin disponer este de conocimiento es imposible poder participar en la toma de decisiones (1).

En diversos estudios se han analizado los elementos que podrían facilitar la muerte en paz; en uno de ellos se efectuaron entrevistas a enfermos crónicos pertenecientes a tres grupos de patologías (enfermos sometidos a diálisis, infección por el VIH y pacientes mayores de 65 años ingresados en una residencia), los resultados mostraron que el factor considerado como más importante era evitar una inadecuada prolongación del proceso de morir y en un segundo lugar y en el mismo nivel, el mantener una sensación de control sobre la situación, no sentirse una carga para los demás y estrechar las relaciones con los seres queridos (3).

Es evidente que el punto de vista de los profesionales sanitarios y de los pacientes suele ser diferente $(4,5)$.

Decidimos realizar un pequeño estudio analizando las opiniones de diversos profesionales médicos que tienen por su trabajo una experiencia frecuente con la problemática de la muerte.

Utilizamos un cuestionario modificado elaborado en Barcelona y publicado en Medicina Clínica hace algún tiempo (6).

Efectuamos un total de 11 preguntas sobre diversos aspectos éticos y personales que podrían ayudarle a morir en paz. Se dirigió al personal médico del Servicio de Urgencias, Medicina Interna y Cuidados Intensivos de un hospital del grupo 2. Se cuantificaba cada respuesta en $\mathrm{O}$ (nada), 1 (un poco), 2 (bastante), 3 (mucho), 4 (muchísimo).

Contestaron el cuestionario un total de 36 médicos, 19 mujeres y 17 hombres, con una edad media de 37,5 años.

Resultados.

Pregunta $l^{a}$ : Pensar que los médicos pueden controlar mi dolor y otros síntomas. Puntuación media de 3 puntos.

Pregunta $2^{a}$ : Pensar que mi sufrimiento en el proceso de morir será corto. La media de puntuación fue de 2,85 puntos.

Pregunta $3^{a}$ : Pensar que podré controlar hasta el final mis pensamientos y funciones fisiológicas: 2,5 puntos.

Pregunta $4^{a}$ : Pensar que mi muerte no supondrá una carga insoportable para mis personas queridas: 3,28 puntos.

Pregunta 5 $5^{a}$ Poder sentirme cerca y estrechar los vínculos afectivos con mis personas queridas: 3 puntos.

Pregunta $6^{a}$ : Pensar que si no tengo una esperanza real de recuperación no se prolongará artificialmente mi vida: 3,1 puntos.

Pregunta $7^{a}$ : Pensar que mi vida ha tenido algún sentido: 2,9 puntos.

Pregunta $8^{a}$ : Creer en otra vida después de la muerte: 2 puntos.

Pregunta $9^{a}$ : No sentirse culpable o sentirme perdonado por conflictos del pasado:2,3 puntos.

Pregunta $10^{a}$ : Pensar que si la situación se hace insoportable podría ser ayudado para morir con rapidez: 2,5 puntos.

Pregunta $l 1^{a}$ : Pensar que podré morir en mi casa: 2,2 puntos.

Resulta curioso el papel no excesivamente relevante que se da a la pregunta número 10 , sobre si podría ser ayudado a morir con rapidez, aunque es necesario recordar que muchos enfermos pre- 
fieren soportar cierto sufrimiento antes de someterse a un estado de inconsciencia irreversible cuando la muerte se aproxima, por lo tanto prefieren una muerte consciente y vivir la experiencia. Por lo tanto medidas tales como la sedación terminal, deben contar con el consentimiento implícito, explícito o delegado del enfermo o bien de su familia cuando este no sea competente, todos ellos muy bien informados y no olvidar que en ocasiones los deseos del enfermo y de la familia pueden ser discordantes y en ese caso, atendiendo al principio de autonomía, los del paciente deben ser prioritarios (7).

Como conclusiones destacamos la importancia secundaria que para el colectivo médico analizado supone el morir en su casa y la existencia de otra vida después de la muerte , siendo lo más valorado las cuestiones que llevan implícita una mayor carga emocional, como son la pregunta $4^{\text {a }}$ (pensar que mi muerte no supondrá una carga insoportable para mis personas queridas) y la pregunta $6^{\mathrm{a}}$ (pensar que sí no tengo una esperanza real de recuperación no se prolongará artificialmente mi vida).

F. Marcos Sánchez, I. Albo Castaño, F. Árbol Linde, A. I. Franco Moreno, A. Viana Alonso, M. A. Barbudo Ousset

Servicios de Medicina Interna, Urgencias. Unidad de Vigilancia Intensiva. Hospital Nuestra Señora del Prado. Talavera de la Reina. Toledo

1. Azulay Tapiero A. Los principios bioéticos: ¿ se aplican en la situación de enfermedad terminal? An Med Interna (Madrid) 2001; 18: 650-654.

2. Bayés R. Los dos objetivos prioritarios de la medicina del sigo XXI. Jano 2000; 58: 2428-2429.

3. Singer PA, Martín DK, Keiner M. Quality end-of-life care. JAMA 1999; 281: $163-168$

4. Larkin M- Physicians and patients need to talk more. Lancet 1997; 349: 1455.

5. Payne SA, Langley-Evans A. Perceptions of a good death: a comparative study of views of hospice, staff and patients. Palliat Med 1996; 10: 307312 .

6. Bayés R, Limonero JT, Romero E, Arranz P. ¿Qué puede ayudamos a morir en paz? Med Clin (Barc) 2000; 115: 579-582.

7. Azulay Tapiero A. La sedación terminal. Aspectos éticos. An Med Interna (Madrid) 2003; 20: 645-649.

\section{Sobre sedación terminal: realidades y hechos, no sólo opiniones}

\section{Sr. Director:}

Recientemente ha sido publicado en su revista un interesante artículo firmado por A. Azulay Tapiero sobre "La sedación terminal. Aspectos éticos" (1). Probablemente no sea azaroso que haya sido incluido por el comité editorial en un apartado de Humanidades Médicas.

La práctica de sedación terminal, como reconoce el autor, es un acto clínico, técnicamente bien delimitado, no diferente de la sedación que practicamos en el paciente quirúrgico o en el área de intensivos, sólo que en este caso lo que se pretende sea superar el sufrimiento humano extremo no evitable de otro modo, y en una persona que, de hecho, está muriendo, agonizante. La única diferencia técnica reside en el hecho de que no revertimos al enfermo moribundo (sería una crueldad inadmisible), dado que esperamos la muerte que, en cualquier caso, está ocurriendo.

Por lo demás, hay otra sensible diferencia: somos mucho más estrictos en las garantías de todo tipo. Nuestro grupo de investigación en Medicina Humana ha publicado tanto el procedimiento técnico como las necesarias garantías, y, lo que realmente importa, los resultados de una serie real, en un artículo "clínico", digamos, estándar (2).

Es necesario evitar la ambiguedad cuando se escribe o habla sobre "sedación terminal". Evidentemente, no es un tipo de eutanasia. No estamos de acuerdo con el enfoque que el autor realiza de forma, en ocasiones equívoca, sobre esta práctica clínica "de último recurso". Nunca debería afirmarse cosas como: “...no deja de ser una práctica muy cercana a la eutanasia" (sic).

Consideramos que la Sedación terminal es una actuación terapéutica farmacológica justificada ante el sufrimiento de un paciente que está muriendo, como último escalón del arsenal terapéutico. Al considerarla como una medida terapéutica más, queda claro que forma parte de la medicina paliativa y, en absoluto, algo ajeno a ella.

Pensamos que la sedación terminal queda bien diferenciada de la eutanasia (ya sea activa, lenta, etc.). Primero: ¿hay "una dosis letal" de medicación? Como el propio autor comenta, la dosis necesaria de fármaco no tiene un techo predefinido, sino que es totalmente variable dependiendo del paciente y del grado de agotamiento de la reserva funcional. Segundo: la sedación terminal no induce la muerte, es el hecho de malmorir la causa de iniciar una sedación terminal, no la consecuencia. Es, de hecho, un síntoma de muerte inminente $(3,4)$.

Existen diversos protocolos para la correcta aplicación de estas medidas. En el nuestro se recoge: "que la enfermedad sea avanzada e irreversible, y que la muerte se prevea inminente". Pero ¿cómo sabemos que la muerte es inminente? Es imposible saber la hora exacta, pero esto no quiere decir que carezcamos de herramientas que nos ayudan a establecer un pronóstico con una certeza más que razonable.

Un requisito clave, por supuesto, es el Consentimiento Informado obtenido del paciente -si su estado realmente lo permite, lo que sucede infrecuentemente-, o su testamento vital (vigente ya en España, aún apenas practicado, o sólo excepcionalmente), o de su familiar allegado. Este, ciertamente, es un aspecto fundamental, y manifiestamente mejorable. Una vez que se den los requisitos necesarios para la aplicación de la sedación terminal según un protocolo establecido y explícito, el médico tiene la autonomía suficiente para realizarla. Como profesionales se nos debería presuponer una adecuada actuación en todas las parcelas de nuestra actividad. La sedación terminal es una medida terapéutica más, de las muy diversas actividades que un médico ejerce al realizar su labor profesional. Debería ser una práctica más extendida. Pero no ayuda la ambiguedad, los siempre discutibles prejuicios morales, la falta de fundamentación bioética, es verdad, y sobre todo, alguna práctica real, no sólo opiniones.

No es tolerable que en los albores del siglo XXI exista un grado de sufrimiento extremo tratable y, sin embargo, tolerado en paciente moribundo alguno.

Parece paradójico que ante aquellos que más lo necesitan persistan el dilema de intervención, la duda metódica continua, y, finalmente, la inacción, la inhibición, y lo que hemos dado en llamar "el malditismo eutanasista" (ese constructo linguístico que paraliza).

Existen soluciones, no sigamos ignorándolas, tampoco las confundamos.

\section{N. Marín-Gámez, J. A. Montes-Romero, J. Gámir-Ruiz, H. Kessel-Sardiñas ${ }^{1}$}

Medicina Interna y ${ }^{\prime}$ Geriatría. Hospital General de Especialidades Torrecárdenas. Almería. Sistema Sanitario Público Andaluz. 
1. Azulay Tapiero A. La sedación terminal. Aspectos éticos. An Med Interna (Madrid) 2003; 20: 645-649.

2. Marín-Gámez N, Kessel-Sardiñas H. Rodríguez-Galdeano M, et al. Sedación terminal: el último recurso ante una mala muerte. Rev Esp Geriatr y Gerontol 2003; 38: 03-09.

3. Marín-Gámez N, Kessel-Sardiñas H, Barnosi-Marín AC, Rodríguez-Galdeano M, el al. Cincuenta y Seis muertes. Rev Esp Geriatr Gerontol 2003; 37: 244-248.

4. Marín-Gámez N, Rodríguez-Galdeano M, Kessel-Sardiñas H, LazoTorres A, Cervantes-Bonet B, Barnosi-Marín AC. "La Muerte Española" según los profesionales sanitarios no médicos. Investig Clin 2003; 6: 130-132.

\section{Sr. Director:}

En relación con la carta de Marín-Gámez et al (1) quisiera hacer los siguientes comentarios:

El artículo al que hacen referencia (2) expresa reflexiones personales. Como es obvio, en ningún momento ha sido mi intención tratar aspectos "clínicos" de la sedación terminal, sino aspectos exclusivamente éticos, que también pueden ser interesantes y válidos para ayudar a reflexionar y suscitar debate. No considero que sea incorrecto manifestar "sólo opiniones", sino todo lo contrario.

Con respecto a las opiniones, uno puede estar de acuerdo con ellas o no, incluso puede respetarlas o no respetarlas, puede rebatirlas con argumentos o no hacerlo, pero nadie debe atribuirse la autoridad para decir lo que debe afirmarse y lo que no debe afirmarse. Reitero mi opinión, que podrá estar equivocada o no: la sedación terminal puede ser una práctica muy cercana a la eutanasia.

La sedación a la que se hace referencia en mi artículo (2) tiene unas características especiales que la hacen muy diferente de la que se pueda aplicar en cualquier otra circunstancia, como en el paciente quirúrgico o en el ingresado en unidades de cuidados intensivos: es irreversible y no se asocia a técnicas de soporte vital. Estas dos características son precisamente las que le confieren una dimensión ética distinta.

La sedación en la situación de enfermedad terminal no es una práctica exclusiva en el proceso agónico, cuando la muerte "está ocurriendo". En la práctica de los cuidados paliativos, la indicación de la sedación debe depender de la refractariedad de un sufrimiento intenso, que puede ser físico y/o psicológico, y del consentimiento del enfermo, y no de la cercanía o lejanía de la muerte. El hecho de que en su protocolo se refleje como condición para su aplicación "que la muerte se prevea inminente" obliga a pensar que se están refiriendo exclusivamente a la sedación en el proceso de la agonía.

La sedación en el proceso agónico, cuando la muerte es inminente y depende del curso evolutivo de la enfermedad, no debería cuestionarse desde el punto de vista ético y debe quedar claro que, en estos casos, la muerte no siempre es consecuencia de la actuación. En esto parece que coincidimos.

El dilema surge cuando su aplicación anticipa la muerte, eventualidad que muchas veces es conocida de antemano. A esta forma de morir se le denomina eutanasia activa indirecta (3) y se dice que el médico no es responsable de la muerte porque no era su intención provocarla, argumento que considero poco coherente porque tampoco es su intención evitarla pudiéndolo hacer. No es posible sostener que no se desea la consecuencia de una acción cuando se sabe que tendrá lugar con toda seguridad y no se evita cuando se dispone de medios para hacerlo. En este contexto, hay que admitir que se está aplicando una eutanasia activa (creo probable que los autores de la crítica piensen que esta "cosa" nunca debería afirmarse), acto siempre doloroso y lamentable ya que supone la pérdida de una vida humana, pero siempre preferible a mantener un sufrimiento intenso, inútil, no deseado por el enfermo y a veces cruel. La vida no debe tener un valor absoluto.

Agradezco sinceramente las críticas realizadas a algunos aspectos de mi artículo y remito a los lectores interesados a una próxima publicación (4), donde se aportan más reflexiones y opiniones, no resultados, relativas a este tema, paradigma de la bioética en cuidados paliativos.

\section{A. Azulay Tapiero}

1. Marín-Gámez N, Montes Romero JA, Gámir Ruiz J, Kessel Sardiñas H. Sobresedación terminal: realidades y hechos, no sólo opiniones. An Med Interna (Madrid) 2004; 21: 206.

2. Azulay Tapiero A. La sedación terminal. Aspectos éticos. An Med Interna (Madrid) 2003; 20: 645-649

3. Tomás-Valiente Lanuza C. Perspectivas actuales y futuras sobre la regulación de la eutanasia en España. Geriatrianet. Revista Electrónica de Geriatría y Gerontología 2001; 3 (2)

4. Azulay Tapiero A. El proceso de decisión médica aplicado a la sedación terminal. Análisis ético. Med Clin (Barc) 2004. En Prensa. 